Artigo Original

Original Article

Marília Zannon de Andrade Figueiredo ${ }^{1}$

Brasilia Maria Chiari²

Bárbara Niegia Garcia de Goulart2,3

Descritores

Transtornos da surdocegueira Comunicação

Transtornos da linguagem Barreiras de comunicação

Keywords

Deaf-blind disorders Communication

Language disorders Communication barriers

Endereço para correspondência: Marília Zannon de Andrade Figueiredo R. Santa Cruz, 785/101, Vila Mariana, São Paulo (SP), Brasil, CEP: 04121-000.

E-mail: mariliazafig@gmail.com

Recebido em: 11/02/2012

\section{Comunicação em adultos surdocegos com síndrome de Usher: estudo observacional retrospectivo}

\author{
Communication in deafblind adults with Usher syndrome: \\ retrospective observational study
}

\section{RESUMO}

Objetivo: Conhecer as características e desafios enfrentados por surdocegos para comunicar-se e locomover-se; avaliar as repercussões da surdocegueira na vida dos sujeitos, especialmente em relação à comunicação e locomoção. Métodos: Relato de série de casos realizado a partir de entrevistas semiestruturadas com questões relativas à funcionalidade da comunicação, com indivíduos com diagnóstico clínico de síndrome de Usher que frequentaram um ambulatório especializado em um serviço universitário, durante o ano de 2007. A amostra foi composta por 11 sujeitos surdocegos portadores da síndrome de Usher, com idades entre 20 e 57 anos (média de 43 anos e $\mathrm{DP}=12,27)$, dos quais $7(63,6 \%)$ eram do gênero feminino. As respostas foram analisadas qualiquantitativamente pela técnica do Discurso do Sujeito Coletivo (DSC). Resultados: Todos os entrevistados referiram que os sintomas visuais e auditivos tiveram início na infância. Dos 11 entrevistados, 6 sentiram que a doença afetou negativamente suas atividades cotidianas, 6 sentiram dificuldade no trabalho, 2 no lazer. Quatro relataram que houve mudança no relacionamento familiar e 5 relataram que não houve mudança na interação com a família e com os amigos. Na análise do discurso, quase $30 \%$ dos entrevistados relataram utilizar-se de formas alternativas de comunicação; $40 \%$ afirmaram deslocar-se sozinho se o trajeto for previamente conhecido. Conclusão: Os indivíduos com síndrome de Usher enfrentam situações desafiadoras nas atividades cotidianas, nos relacionamentos pessoais, no trabalho e no lazer. Formas alternativas de comunicação são muito utilizadas quando a comunicação oral não é possível. A maioria dos entrevistados referiu independência de locomoção, ou procurava alcançá-la.

\begin{abstract}
Purpose: To characterize the communication and the main mechanisms that facilitate interpersonal relationships of deafblind, especially in relation to communication and locomotion and the impact of these aspects on deafblindness. Methods: Report of a series of cases conducted from semi-structured interviews with questions relating to the functionality of communication, with Usher syndrome patients attended in a specialized clinic in a university service, in the year 2007. The sample consisted of 11 deafblind subjects, with Usher syndrome, aged between 20 and 57 years (mean age 43 years and SD=12.27), of which 7 (63.6\%) were female. The responses were analyzed by qualitative-quantitative technique of the Discurso do Sujeito Coletivo (DSC). Results: All participants reported that visual and auditory symptoms began in childhood. Of the 11 interviewed, 6 reported that the disease has negatively affected their daily activities, 6 experienced difficulty at work, and 2 at leisure. Four reported that there was a change in family relationships, and 5 reported no change in the interaction with family and friends. In discourse analysis, almost $30 \%$ of respondents reported to use alternative forms of communication, $40 \%$ said move alone if the way is known before. Only 1 of 11 participants said they did not ask for help when needed. Conclusion: Individuals diagnosed with Usher syndrome face challenging situations in daily activities, personal relationships, at work and at play. Alternative forms of communication are often used when verbal communication is not possible. The majority of respondents have independence of locomotion, or seeking ways to achieve it.
\end{abstract}

Trabalho realizado na Universidade Federal de São Paulo - UNIFESP - São Paulo (SP), Brasil.

(1) Programa de Pós-graduação, Departamento de Fonoaudiologia, Universidade Federal de São Paulo UNIFESP - São Paulo (SP), Brasil.

(2) Departamento de Fonoaudiologia, Universidade Federal de São Paulo - UNIFESP - São Paulo (SP), Brasil. (3) Universidade Federal do Rio Grande do Sul - UFRGS - Porto Alegre (RS), Brasil.

Conflito de interesses: nada a declarar. 


\section{INTRODUÇÃO}

As deficiências auditiva e visual prejudicam duas importantes modalidades sensoriais. A surdocegueira é uma deficiência singular, com distintos graus de perdas visuais e auditivas concomitantemente. Os déficits auditivo e visual acarretam sérios problemas de comunicação, mobilidade e acesso à informação ${ }^{(1,2)}$.

As causas da surdocegueira estão vinculadas, segundo autores $^{(3)}$, às anomalias de desenvolvimento, à infecção transplacentária, às infecções neonatais, aos erros inatos de metabolismo, aos traumatismos e às síndromes. Dentre essas causas, a mais comum é a síndrome de Usher, uma doença hereditária, com três tipos clínicos distintos, que, em síntese, causa perda auditiva neurossensorial, retinose pigmentar e alterações vestibulares ${ }^{(4-6)}$.

O Tipo I acarreta deficiência auditiva neurossensorial severa a profunda não progressiva, com início da Retinose Pigmentar entre os 8 e 15 anos de idade, resposta vestibular alterada (dificuldade na marcha e incoordenação de movimentos) e diminuição visual noturna durante a infância; o Tipo II, deficiência auditiva neurossensorial leve a moderada não progressiva, com início de Retinose Pigmentar depois dos 15 anos de idade, resposta vestibular normal, escotomas no final da infância, chegando à deficiência visual total na idade adulta; o Tipo III, deficiência auditiva neurossensorial progressiva, com idade variável para o início da Retinose Pigmentar, resposta vestibular normal ou alterada, diminuição visual noturna na infância ou adolescência, escotomas no final da adolescência, chegando à deficiência visual total na idade adulta. Estima-se que, aproximadamente, um terço dos casos correspondem ao Tipo I e dois terços, ao Tipo II; sendo o tipo III pouco frequente ${ }^{(4-6)}$.

As pessoas surdocegas necessitam de formas específicas de comunicação para terem acesso a educação, lazer, trabalho e vida social ${ }^{(7)}$. O conhecimento das habilidades e dificuldades de comunicação de indivíduos surdocegos pode nortear as políticas públicas na criação de medidas que visem melhorar o seu acesso à comunicação e à informação e, assim, a sua independência.

Desta forma, são objetivos do presente estudo: 1) conhecer as características e desafios enfrentados por surdocegos para comunicar-se e locomover-se; 2) avaliar as repercussões da surdocegueira na vida dos sujeitos, especialmente em relação à comunicação e locomoção.

\section{MÉTODOS}

Para a presente pesquisa, aprovada pelo Comitê de Ética em Pesquisa sob número 1623/10, foram utilizadas entrevistas que se encontram arquivadas no banco de dados do Laboratório de Investigação dos Distúrbios da Audição e da Linguagem da UNIFESP. Devido à raridade da condição patológica, as entrevistas contemplaram todos os surdocegos com diagnóstico clínico de síndrome de Usher que frequentaram o referido Laboratório e o Grupo Brasil de Apoio ao Surdocego e ao Múltiplo Deficiente Sensorial durante o ano de 2007 e foram realizadas, naquele ano, por alunos de graduação do curso de Fonoaudiologia da instituição, com treinamento prévio para a realização das avaliações, supervisionados por fonoaudiólogo com experiência de mais de 20 anos na avaliação e reabilitação dos distúrbios da linguagem relacionados à perda auditiva.

A amostra foi composta pelo universo de entrevistados: 11 sujeitos surdocegos com diagnóstico clínico de síndrome de Usher, com idades entre 20 e 57 anos (média de 43 anos e $\mathrm{DP}=12,27)$, dos quais $7(63,6 \%)$ eram do gênero feminino. $\mathrm{O}$ banco de dados no qual esta pesquisa se baseou não dispunha de dados sociodemográficos dos entrevistados, tais como renda e escolaridade, nem de dados individuais quanto ao grau e tipo da síndrome.

As entrevistas foram realizadas individualmente ou com o auxílio de um intérprete (quando necessário), e o questionário semiestruturado ${ }^{(8)}$ continha as seguintes perguntas: 1) Como você se comunica no dia-a-dia?; 2) Como você faz para chegar ao local onde precisa ir?; 3) Como e quando você percebeu a sua dificuldade para ouvir?; 4) Como e quando você percebeu a sua dificuldade para enxergar?; 5) Como e quando você descobriu que tinha síndrome de Usher?; 6) Depois que a doença foi diagnosticada pelo médico, o que mudou no seu dia-a-dia?; 7) O que você faz quando precisa de ajuda?; 8) Dentre as suas dificuldades de visão e audição, qual você acha que é pior? Por quê?

Como nas questões de número $3,4,5$ e 6 , os entrevistados foram indagados quanto ao início dos sintomas auditivos e visuais, quanto ao conhecimento da síndrome de Usher e quanto às mudanças que a surdocegueira ocasionou em suas vidas; tais questões foram utilizadas para caracterizar a amostra.

Todos os entrevistados referiram que os sintomas visuais e auditivos tiveram início na infância, sendo que um deles informou que, na idade adulta, apresentou também outra doença ocular, a catarata. Um dos entrevistados não respondeu à pergunta relacionada ao início dos sintomas auditivos.

Em relação à síndrome de Usher, 7 (63,63\%) conheceram o diagnóstico da doença com essa denominação na idade adulta, $3(27,27 \%)$ desconheciam essa síndrome e 1 (9,09\%) dos entrevistados não respondeu à questão.

Para análise das respostas obtidas com as questões de número 1,2, 7 e 8, foi utilizada uma modalidade qualiquantitativa de análise do discurso, o Discurso do Sujeito Coletivo (DSC) ${ }^{(9)}$. O DSC é um discurso-síntese elaborado com partes de discursos de sentido semelhante, por meio de procedimentos sistemáticos e padronizados ${ }^{(9)}$.

A técnica consiste basicamente em analisar o material verbal coletado em pesquisas que têm depoimentos como sua matéria-prima, extraindo-se de cada um desses depoimentos as Ideias Centrais ou Ancoragens e as suas correspondentes Expressões-Chave ${ }^{(9)}$.

As Expressões-Chave são trechos do discurso, destacados pelo pesquisador, que revelam a essência do seu conteúdo. Para categorizar tais expressões, os trechos com ideias semelhantes ou complementares são agrupados sob uma mesma Ideia Central. Quando essas expressões remetem a uma certa teoria ou ideologia que o autor do discurso professa e que está embutida no seu discurso como se fosse uma afirmação qualquer, dá-se o nome de Ancoragem ${ }^{(9)}$.

O DSC é, portanto, uma reunião, em um só discurso-síntese redigido na primeira pessoa do singular, de Expressões-Chave 
que têm Ideias Centrais ou Ancoragens semelhantes ou complementares $^{(9)}$.

Questões relativas ao coletivo podem ser mais adequadamente exploradas a partir de metodologias qualitativas ou qualiquantitativas, como o DSC, especialmente quando as percepções das pessoas em geral sobre um dado assunto e, mais particularmente, dos pacientes sobre sua doença e as implicações que elas the acarretam são objeto de estudo ${ }^{(10-12)}$. Esse tipo de metodologia vem sendo cada vez mais utilizado na Oftalmologia ${ }^{(13-15)}$ e na Fonoaudiologia ${ }^{(8,16,17)}$.

\section{RESULTADOS}

Quanto às repercussões da doença no dia-a-dia, segundo a percepção dos entrevistados, todos referiram mudança negativa em pelo menos um dos aspectos analisados (atividades cotidianas, aspectos relacionais com família e amigos, trabalho e lazer). As dificuldades referidas foram desde o isolamento no círculo familiar e de amizades, até a impossibilidade de continuar no trabalho, passando por dificuldades de locomoção dentro ou fora de casa. Também comentaram sobre a dificuldade em realizar tarefas simples do cotidiano, bem como em acompanhar noticiários televisivos, ler livros e ouvir músicas. A maioria afirmou pedir ajuda sempre que necessário.

A questão 1, "Como você se comunica no dia-a-dia?", gerou 8 discursos do sujeito coletivo, distribuídos nas respectivas ideias centrais (Tabela 1).

Tabela 1. Distribuição das ideias centrais obtidas com a questão 1

\begin{tabular}{llcc}
\hline Ideia Central & $\mathrm{n}$ & $\%$ \\
\hline A & Não há muita conversa. & 2 & 10,53 \\
B & Usando formas alternativas de comunicação. & 5 & 26,32 \\
C & O outro deve ficar próximo. & 3 & 15,79 \\
D & O outro deve falar alto e devagar. & 3 & 15,79 \\
E & Por meio da fala. & 3 & 15,79 \\
F & O outro deve ter paciência. & 1 & 5,25 \\
G & O outro não deve gritar. & 2 & 10,53 \\
\hline
\end{tabular}

O DSC B (Usando formas alternativas de comunicação) foi a ideia mais compartilhada $(26,32 \%)$, resultando no discurso abaixo:

Tudo em sinais, né? Se a pessoa não sabe os sinais, faço qualquer coisa, escrevo, ou uso um intérprete... Tem a Língua de sinais tátil, alfabeto manual na mão, prática de leitura com lupa eletrônica, né, computador configurado para enviar e receber os e-mails, braile... Mas é difícil, né, tem que treinar. Para quem nasce cego é mais fácil, mas para quem tá aprendendo é difícil...

Tem o Tadoma, que é uma forma de entender o que as pessoas falam, tocando na pessoa, através da articulação labial e vibração.

Foram obtidos 4 DSC referentes à questão 2, "Como você faz para chegar ao local onde precisa ir?", distribuídos nas respectivas ideias centrais (Tabela 2).
Tabela 2. Distribuição das ideias centrais obtidas com a questão 2

\begin{tabular}{llcc}
\hline Ideia Central & $\mathrm{n}$ & $\%$ \\
\hline A & Ando sozinho, a pé ou no transporte público, & 7 & 36,84 \\
& desde que o trajeto seja conhecido. & & \\
B & Quando necessário, peço ajuda. & 5 & 26,32 \\
C & Estou treinando orientação e mobilidade. & 3 & 15,79 \\
D & Acompanhado, na maioria dos casos. & 4 & 21,05 \\
\hline
\end{tabular}

O DSC A (Ando sozinho, a pé ou no transporte público, desde que o trajeto seja conhecido) foi a ideia mais compartilhada $(36,84 \%)$, resultando no discurso abaixo:

Ando normal... Depende do local, tenho que saber onde que é primeiro... Certas distâncias também... Eu ando de ônibus sozinho. A maioria dos motoristas não para fora do ponto de ônibus. Mas, na verdade, eu nunca peguei o ônibus errado. O metrô é a coisa mais fácil... Ando a pé, de ônibus e metrô... Ando normal em caminhos que conheço. Quando não conheço, não vou.

Se for lugar acostumado, eu já tenho a técnica por causa da bengala... Dá pra mim ir... Ando de ônibus também... E, no metrô, às vezes eu ouço a estação, mas, às vezes, eu não ouço. Aí eu conto, já tenho memorizado... Aí eu desço certo. Não erro. Se for uma área de risco, onde é um lugar isolado, eu não conheço, tem que ser acompanhado...

O brasileiro, apesar de ser solidário, olha minha fisionomia, eles acham que eu não preciso de ajuda. Então, nesse caso, já também prefiro não pedir ajuda, é mais fácil eu embarcar no ônibus no início e desembarcar em qualquer ponto... Ando de metrô, trem.

Deve-se observar que, nesse discurso, apareceu uma Ancoragem, expressando a teoria de que o povo brasileiro é solidário: "O brasileiro, apesar de ser solidário, olha minha fisionomia, eles acham que eu não preciso de ajuda."

A questão 7, "O que você faz quando precisa de ajuda?", gerou 4 DSC, distribuídos nas respectivas ideias centrais (Tabela 3).

Tabela 3. Distribuição das ideias centrais obtidas com a questão 7

\begin{tabular}{llcc}
\hline Ideia Central & $\mathrm{n}$ & $\%$ \\
\hline A & Não peço ajuda. & 1 & 9,09 \\
B & Falo sobre a deficiência e peço ajuda. & 4 & 36,36 \\
C & Escrevo que preciso de ajuda. & 2 & 18,18 \\
D & Vou atrás de alguém que possa ajudar. & 4 & 36,36 \\
\hline
\end{tabular}

O DSC B (Falo sobre a deficiência e peço ajuda) e o DSC $\mathrm{D}$ (Vou atrás de alguém que possa ajudar) foram as ideias mais compartilhadas (36,36\%).

Abaixo, o DSC B:

Peço ajuda direto, para o pessoal do metrô, para as pessoas. Falo que sou surdo e peço para alguém ligar para a mãe, peço para ela ir me buscar ou aviso que vou chegar atrasada. Sempre pego um telefone ou saio gritando pelo mundo afora: "Preciso de ajuda"! 
Chego até a pessoa e me identifico como surdocego. Alguns não acreditam, ficam assustados; mas eles ajudam. Lá em casa, por exemplo, eu posso contar com qualquer um deles... eu digo assim quando eu to precisando de ajuda: "Ô menina, faz favor, me empresta seus olhos aî̉. Aí minha mãe vem. Parece uma brincadeira, mas eu sempre levo isso aí de bom humor.

\section{DSC D:}

Em casa, se for preciso, eu peço ajuda pra algum vizinho. Na rua, é a mesma coisa, eu procuro localizar alguém que esteja do meu lado pra pedir ajuda... eu vou atrás de quem pode me ajudar...

Para a questão 8, "Dentre as suas dificuldades de visão e audição, qual você acha que é pior? Por quê?", foram obtidos 5 DSC, distribuídos nas respectivas ideias centrais (Tabela 4).

Tabela 4. Distribuição das ideias centrais obtidas com a questão 8

\begin{tabular}{llcc}
\hline Ideia Central & $\mathrm{n}$ & $\%$ \\
\hline A & A audição. & 3 & 27,27 \\
B & A visão. & 5 & 45,45 \\
C Nenhuma, aceito minha condição. & 1 & 9,09 \\
D Ambos. & 1 & 9,09 \\
E & Questão não respondida. & 1 & 9,09 \\
\hline
\end{tabular}

O DSC B (A visão) foi a ideia mais compartilhada $(45,45 \%)$, resultando no discurso abaixo:

Dessas duas deficiências? Ah, a visão é o pior... O maior sonho da minha vida é enxergar pelo menos mais uns $20 \%$ a mais. Aí eu seria um homem muito feliz, viu? Porque a audição... a gente já acostumou, desde pequeno. Às vezes, a gente ta olhando, ta andando no trânsito e vê as pessoas brigando no trânsito, fala mal, fala aquele palavrão, coisa que a gente não quer ouvir. Como a gente já tem dificuldade de ouvir, vai embora. Entendeu? Então, acho que a audição pra mim não é problema. Quer dizer, não é que eu não necessito da audição, né? Mas igual à visão acho que não. A visão pra mim é um fator principal. Mesmo que a gente não ouve, ainda ta vendo, né? Eu dependo de pessoas pra me comunicar, pra sair, pra tudo. Mesmo que eu não escute, se eu ver ainda, dá pra eu me virar, fazer as coisas.

\section{DISCUSSÃO}

O fato de quase $30 \%$ dos entrevistados não saberem o que é a síndrome de Usher ou terem apenas informações parciais sobre a doença indica a necessidade de melhorar a comunicação dos profissionais de saúde com os pacientes.

Aproximadamente $30 \%$ dos entrevistados relataram utilizarse de formas alternativas de comunicação, seja sem ou com o auxílio de dispositivos eletrônicos. A comunicação é uma das necessidades básicas do ser humano. Os surdocegos necessitam de facilitadores na comunicação para terem acesso a educação, lazer, trabalho e vida social( ${ }^{(7)}$.
Um indivíduo surdo acostumado a utilizar pistas visuais na comunicação pode ter dificuldades significativas de comunicar-se quando ocorre uma deficiência visual. Nenhum tratamento tem se mostrado efetivo para retinose pigmentar, mas os pacientes podem ter maior qualidade de vida com o uso de auxílios ópticos.

Embora a comunicação seja talvez o principal problema enfrentado pela população surdocega, muitas outras dificuldades surgem na locomoção, educação, emprego e atividades de vida diária ${ }^{(2,18)}$. De fato, a maioria dos entrevistados sentiu que a surdocegueira afetou suas atividades cotidianas, trabalho e lazer e seus relacionamentos interpessoais.

O sistema visual é essencial para uma locomoção segura e eficiente, como evidenciado pela redução no desempenho de mobilidade em pessoas que são deficientes visuais ${ }^{(19,20)}$. Com a visão, um indivíduo pode adquirir informações sobre o ambiente que o cerca, planejar seu caminho, detectar obstáculos e, posteriormente, evitá-los.

Sabe-se que o sistema vestibular também é imprescindível para uma locomoção adequada e que indivíduos com síndrome de Usher podem apresentar uma resposta vestibular alterada ${ }^{(4-6)}$. Assim, além de a locomoção ser prejudicada pelo déficit visual, em muitas situações ocorre incoordenação da marcha. Entretanto, no banco de dados no qual este estudo se baseou, não se encontram disponíveis os dados sobre o sistema vestibular dos entrevistados.

No presente estudo, quase $40 \%$ dos entrevistados afirmaram deslocar-se sozinhos se o trajeto for previamente conhecido; quase $30 \%$ afirmaram pedir ajuda quando necessário e alguns afirmaram dependência de companhia para deslocar-se.

Quando o indivíduo apresenta dificuldade para andar e se locomover independentemente, devido à perda de campo visual, deve ser encaminhado a um serviço de reabilitação de orientação e mobilidade ${ }^{(21)}$. No presente estudo, aproximadamente $15 \%$ dos entrevistados estão fazendo curso de orientação e mobilidade.

Ainda com relação à questão sobre deslocamento, apareceu a Ancoragem "o brasileiro é um povo solidário". Ancoragem é a expressão de uma dada teoria ou ideologia que o autor do discurso professa e que está embutida no seu discurso como se fosse uma afirmação qualquer ${ }^{(22)}$. A Ancoragem presente no discurso tem suporte no relatório mundial do Global Entrepreneurship Monitor (GEM) ${ }^{(23)}$, no qual o povo brasileiro foi apontado como sendo um dos mais solidários do mundo.

Apenas um dos entrevistados afirmou não pedir auxílio. Os demais entrevistados afirmaram procurar ajuda, seja falando ou escrevendo suas necessidades.

Quase metade dos entrevistados acha que a falta da visão é o que mais atrapalha. Conforme foi discutido acima, a deficiência visual na síndrome de Usher acarreta dificuldade de localização de objetos, locomoção e mobilidade, sendo necessários a reabilitação visual e o treinamento de orientação e mobilidade para uma melhor qualidade de vida.

Para 30\% dos entrevistados, a falta da audição é pior. Sem a audição, o indivíduo não consegue escutar sons de alerta e nem se comunicar por meio da fala. A privação sensorial auditiva afeta também o modo de se relacionar com seu meio e sua 
cultura $^{(24)}$. Um dos entrevistados afirmou sentir falta de ambos; e outro afirmou estar adaptado a suas deficiências.

Alguns estudos foram realizados com o objetivo de investigar a relação entre funcionamento psicossocial e perda sensorial dupla (visual e auditiva) em idosos. Carabellese et al. ${ }^{(25)}$ realizaram uma pesquisa com 1.191 idosos não institucionalizados, com idade entre 70 e 75 anos, no norte da Itália, e tiveram como objetivo determinar a associação entre medidas de qualidade de vida e deficiência sensorial em idosos que vivem em casa. Os resultados deste estudo mostraram que qualidade de vida está significativamente ligada à perda de audição e visão. Particularmente, o humor e as relações sociais foram afetados pela perda de visão, enquanto que a independência em atividades de vida diária foi fortemente relacionada à deficiência auditiva. Luey ${ }^{(26)}$ também confirmou a relação entre o desempenho psicossocial pobre e perdas sensoriais em um estudo com 30 pessoas com perda sensorial dupla. Os resultados revelaram que todos os sujeitos sentiam-se isolados, frustrados, vulneráveis, entediados, deprimidos, amargos e raivosos, por consequência de sua perda auditiva e visual.

Oppegard et al. ${ }^{(27)}$ exploraram a relação entre perdas auditivas e visuais, apoio social, depressão e ansiedade em 102 moradores de uma comunidade, com idade entre 60 e 92 anos. Os resultados revelaram que a perda sensorial estava moderadamente relacionada à depressão e ansiedade em sujeitos com pouco apoio social e cuidados. Além disso, segundo Ravish ${ }^{(28)}$, idosos com perda sensorial são particularmente suscetíveis ao isolamento social.

Pouco se sabe sobre os efeitos funcionais no cotidiano de indivíduos surdocegos. Há muitas ferramentas para avaliar a restrição às atividades em indivíduos cegos ou surdos, mas estas não são aplicáveis quando as duas deficiências estão presentes. Precisam ser realizadas mais pesquisas sobre os efeitos funcionais da surdocegueira. Tais estudos também deverão abordar fatores como idade, cognição, personalidade e duração da incapacidade, pois estes provavelmente afetarão a eficácia da reabilitação ${ }^{(29)}$. A intervenção deve abordar as necessidades do surdocego hierarquicamente, com níveis de independência realistas, para otimizar a qualidade de vida e bem-estar, sendo necessária uma equipe multidisciplinar ${ }^{(2)}$.

Os recentes avanços da genética têm aumentado a atenção para diferentes tipos de deficiências e disfunções que podem coexistir com deficiência auditiva. Em média, os surdos tendem a ter defeitos visuais em uma taxa maior do que suas contrapartes no grupo etário na população em geral ${ }^{(18)}$. Autores sugerem a realização de vários exames físicos em todas as crianças surdas, incluindo estudos genéticos não só das crianças, mas também de seus pais e outros membros da família ${ }^{(18)}$.

O banco de dados no qual esta pesquisa se baseou não dispunha de dados sociodemográficos dos entrevistados, tais como renda e escolaridade, nem de dados individuais quanto ao grau e tipo da síndrome, aspectos que limitaram o estudo. Acreditamos que, com uma caracterização mais completa da amostra, os resultados poderiam ser mais bem discutidos.

\section{CONCLUSÕES}

Os indivíduos com diagnóstico clínico de síndrome de Usher enfrentam situações desafiadoras nas atividades cotidianas, nos relacionamentos pessoais, no trabalho e no lazer. As dificuldades referidas foram desde o isolamento no círculo familiar e de amizades, até a impossibilidade de continuar no trabalho, passando por dificuldades de locomoção dentro ou fora de casa. Também comentaram sobre a dificuldade em realizar tarefas simples do cotidiano, bem como em acompanhar noticiários televisivos, ler livros e ouvir músicas. A maioria afirmou pedir ajuda sempre que necessário.

Para comunicar-se, os entrevistados que apresentavam um grau de comprometimento menor ainda utilizavam a comunicação oral (fala), enquanto outra parte dos entrevistados utilizavam formas alternativas de comunicação, com ou sem o auxílio de dispositivos eletrônicos.

A maioria dos entrevistados referiu independência de locomoção, ou estava buscando formas de alcançá-la, como o curso de orientação e mobilidade.

*MZAF foi responsável pela tabulação, análise e interpretação dos dados e redação do manuscrito; BMC e BNGG foram responsáveis pela supervisão e orientação geral das etapas de execução do estudo e de elaboração do manuscrito.

\section{REFERÊNCIAS}

1. Hoevenaars-van den Boom MAA, Antonissen ACFM, Knoors H, Vervloed MPJ. Differentiating characteristics of deafblindness and autism in people with congenital deafblindness and profound intellectual disability. J Intellect Disabil Res. 2009;53(6):548-58.

2. Heine $\mathrm{C}$, Browning CJ. Communication and psychosocial consequences of sensory loss in older adults: overview and rehabilitation directions. Disabil Rehabil. 2002;24(15):763-73.

3. Grasland A, Pouchot J, Hachulla E, Blétry O, Papo TE, Vinceneux P. Typical and atypical cogan's syndrome: 32 cases and review of the literature. Rheumatology. 2004;43(8):1007-15.

4. Pennings RJ, Fields RR, Huygen PL, Deutman AF, Kimberling WJ, Cremers CW. Usher syndrome type III can mimic other types of Usher syndrome. Ann Otol Rhinol Laryngol. 2003;112(6):525-30.

5. Pennings RJ, Huygen PL, Weston MD, van Aarem A, Wagenaar M, Kimberling WJ, et al. Pure tone hearing thresholds and speech recognition scores in Dutch patients carrying mutations in the USH2A gene. Otol Neurotol. 2003;24(1):58-63.

6. Reisser CFV, Kimberling WJ, Otterstedde CR. Hearing loss in Usher syndrome type II is nonprogressive. Ann Otol Rhinol Laryngol. 2002;111(12 Pt 1):1108-11

7. Szlyk JP, Seiple W, Fishman GA, Alexander KR, Grover S, Mahler CL. Perceived and actual performance of daily tasks: relationship to visual function tests in individuals with retinitis pigmentosa. Ophthalmology. 2001;108(1):65-75.

8. Chiari BM, Bragatto EL, Carvalho CAF, Nishihata R. Perspectivas da Atuação Fonoaudiológica diante do Diagnóstico e Prognóstico da Surdocegueira. Distúrbios da Comunicação. 2006;18(3):371-82.

9. Lefèvre F, Lefèvre AMC. O discurso do sujeito coletivo: um novo enfoque em pesquisa qualitativa. Caxias do Sul: Educs; 2003. 
10. Rocha EM, Alves M. Metodologia qualitativa. In: Bicas HEA, Rodrigues MLV, editores. Metodologia científica. Rio de Janeiro: Cultura Médica; 2008. p. 337-40.

11. Minayo MCS. O Desafio do Conhecimento. Pesquisa Qualitativa em Saúde. $8^{\text {a }}$ ed. São Paulo: Hucitec;2004.

12. Turato ER. Tratado da metodologia da pesquisa clínico-qualitativa. São Paulo: Vozes; 2003.

13. Silva LR, Paula JS, Rocha EM, Rodrigues MLV. Fatores relacionados à fidelidade ao tratamento do glaucoma: opiniões de pacientes de um hospital universitário. Arq Bras Oftalmol. 2010;73(2):116-9.

14. Carvalho RS, Temporini AR, Kara-José N. Assessment of visual health campaign activities at school teachers perception. Arq Bras Oftalmol. 2007;70(2):239-45.

15. Kara-José N, Alves MR, Temporini ER. Características e percepções de pais de escolares portadores de problemas oculares atendidos em projeto comunitário. Rev Bras Oftalmol. 2000;59(2):99-104.

16. Lemos MES, Barros CGC, Amorim RHC. Representações familiares sobre as alterações no desenvolvimento da linguagem de seus filhos. Distúrbios da Comunicação. 2006;18(3):323-33.

17. Trenche $\mathrm{MCB}$, Balieiro CR. A escrita e prática fonoaudiológica com crianças surdas/deficientes auditivas. Distúrbios da Comunicação. 2004;16(2):175-80.

18. Maia SR, Araoz SMM, Ikonomidis VM. Surdocegueira e Deficiência Múltipla Sensorial: sugestões de recursos acessíveis e estratégias de ensino. São Paulo: Grupo Brasil; 2010.

19. Schein JD, Miller MH. Genetics and deafness: implications for education and life care of deaf students. Am Ann Deaf. 2008;153(4):408-10.
20. Geruschat DR, Turano KA, Stahl JW. Traditional measures of mobility performance and retinitis pigmentosa. Optom Vis Sci. 1998;75(7):525-37.

21. Brabyn JA, Schneck ME, Haegerstrom-Portnoy G, Lott LA. Dual Sensory Loss: Overview of Problems, Visual Assessment, and Rehabilitation. Trends Amplif. 2007;11(4):219-26.

22. Lefèvre F, Lefèvre AMC. Depoimentos e discursos. Brasília: Liberlivro; 2005.

23. GEM: Global Entrepreneurship Monitor [Internet]. [cited May 2011]. Available from: http://www.gemconsortium.org.

24. Silman S, Iorio MCM, Mizhahi MM, Parra VM. Próteses auditivas: um estudo sobre seu benefício na qualidade de vida de indivíduos portadores de perda auditiva neurossensorial. Distúrbios da Comunicação. 2004;16(2):153-65.

25. Carabellese C, Appollonio I, Rozzini R, Bianchetti A, Frisoni GB, Frattola L, et al. Sensory impairment and quality of life in a community elderly population. J Am Geriatr Soc. 1993;41(4):401-7.

26. Luey HS. Sensory loss: a neglected issue in social work. Journal of Gerontological Social Work. 1994;21(3-4):213-23.

27. Oppegard K, Hansson RO, Morgan T, Indart M, Crutcher M, Hampton P. Sensory loss, family support, and adjustment among the elderly. J Soc Psychol. 1984;123(2D Half):291-2.

28. Ravish T. Prevent social isolation before it starts. J Gerontol Nurs. 1985;11(10):10-3.

29. Saunders GH, Echt KV. An Overview of Dual Sensory Impairment in Older Adults: Perspectives for Rehabilitation. Trends Amplif. 2007;11(4):243-58. 